\title{
Neonatal resuscitation in global health settings: an examination of the past to prepare for the future
}

\author{
Beena D. Kamath-Rayne ${ }^{1}$, Sara K. Berkelhamer ${ }^{2}$, Ashish KC ${ }^{3}$, Hege L. Ersdal ${ }^{4}$ and Susan Niermeyer ${ }^{5}$
}

As rates of childhood mortality decline, neonatal deaths account for nearly half of under-5 deaths worldwide. Intrapartum-related events (birth asphyxia) contribute to approximately one-quarter of neonatal deaths, many of which can be prevented by simple resuscitation and newborn care interventions. This paper reviews various lines of research that have influenced the global neonatal resuscitation landscape. A brief situational analysis of asphyxia-related newborn mortality in low-resource settings is linked to renewed efforts to reduce neonatal mortality in the Every Newborn Action Plan. Possible solutions to gaps in care are identified. Building on international scientific evidence, tests of educational efficacy, and community-based trials established the feasibility and effectiveness of training in resource-limited settings and identified successful implementation strategies. Implementation of neonatal resuscitation programs has been shown to decrease intrapartum stillbirth rates and early neonatal mortality. Challenges remain with respect to provider competencies, coverage, and quality of interventions. The combination of resuscitation science, strategies to increase educational effectiveness, and implemention of interventions with high coverage and quality has resulted in reduced rates of asphyxia-related neonatal mortality. Further efforts to improve coverage and implementation of neonatal resuscitation will be necessary to meet the 2035 goal of eliminating preventable newborn deaths.

$\mathbf{R}$ eduction in neonatal mortality rose to prominence on the global health agenda with the declaration of the Millennium Development Goals during the 2000 United Nations General Assembly. Specifically, Millennium Development Goal-4 targeted a two-thirds reduction in the global under-5 mortality rate from 1990 to 2015. Although remarkable progress has been made with respect to decreasing childhood mortality, the rate of reduction in neonatal mortality has been notably slower, so that neonatal deaths now comprise $\sim 45 \%$ of all childhood deaths $(1,2)$. Post 2015 , the Sustainable Development Goals and the Every Newborn
Action Plan set new targets for national neonatal mortality rates of less than 10 neonatal deaths per 1,000 live births, with reduction of global rates from $\sim 20$ per 1,000 live births in 2015 to 7 per 1,000 live births by 2035 (Figure 1) (3). In 2013, birth-asphyxia-related neonatal deaths accounted for $\sim 662,000$ deaths or $11 \%$ of under-5 deaths, indicating that further improvement in this area will have a critical role in reaching the 2035 targets (2).

Intrapartum-related deaths encompass both fresh stillbirths and early neonatal deaths. Recent estimates suggest that half of stillbirths occur intrapartum, accounting for $\sim 1.3$ million deaths annually (4). Complicating matters, many asphyxiarelated early neonatal deaths in resource-limited settings historically have been misclassified as fresh stillbirths (5). Adequate basic neonatal resuscitation can prevent many intrapartum-related deaths and reduce such misclassification, but reduction of true intrapartum stillbirth also requires adequate antenatal and obstetric care during labor. Skilled birth attendance and newborn resuscitation are evidencebased interventions directed at the moment when the lifetime risk for mortality is highest: the day of birth $(6,7)$. The challenge of delivering these interventions, however, is complicated by the fact that in some areas up to $60 \%$ of births occur outside of health facilities, and the quality of care in facilities may be lacking (8). In particular, implementation of properly performed neonatal resuscitation remains low in countries with the highest neonatal mortality rates (8), with studies estimating an additional $20-40 \%$ neonatal lives saved with adequate coverage of basic neonatal resuscitation at all sites where a baby may be born $(6,7)$. With the goal of improving global newborn health, understanding the impact that neonatal resuscitation delivered by trained health workers can have on asphyxia-related mortality remains a research priority (9).

Moving forward, further gains in reducing neonatal mortality will depend on the synergy between medical, educational, and implementation research. We seek to review the changes in the global landscape of neonatal resuscitation that have been driven by evaluation of evidence around resuscitation science, training in neonatal resuscitation, and

\footnotetext{
${ }^{1}$ Perinatal Institute and Global Child Health, Cincinnati Children's Hospital Medical Center, Cincinnati, Ohio; ${ }^{2}$ Division of Neonatology, University at Buffalo, SUNY, Buffalo, New York; ${ }^{3}$ Health Section, UNICEF Nepal, Uppsala, Sweden; ${ }^{4}$ Department of Anaesthesiology and Intensive Care, Stavanger University Hospital, Stavanger, Norway; ${ }^{5}$ Department of Pediatrics, Section of Neonatology, University of Colorado School of Medicine, Colorado School of Public Health, Aurora, Colorado. Correspondence: Beena D. Kamath-Rayne (Beena.Kamath-Rayne@cchmc.org) 
implementation of programs focusing on care at birth. We will detail the successes achieved, and suggest further research to help attain the goals of the Every Newborn Action Plan.

\section{ORIGINS OF NEONATAL RESUSCITATION TRAINING WORLDWIDE}

The first standardized training program for resuscitation at birth, the American Academy of Pediatrics Neonatal Resuscitation Program (NRP), was released in 1987 with the goals of promoting evidence-based care and ensuring that at least one professional trained in neonatal resuscitation was present at every delivery in the United States (Figure 2) (10). NRP brought a new focus on skill acquisition and aligned the knowledge and skills taught with the professional responsibilities of health-care providers. Hands-on learning with mannequins and a simple, transportable program structure led to widespread adoption outside the United States. The use of NRP globally increased rapidly, as implementing countries enjoyed the autonomy of owning,

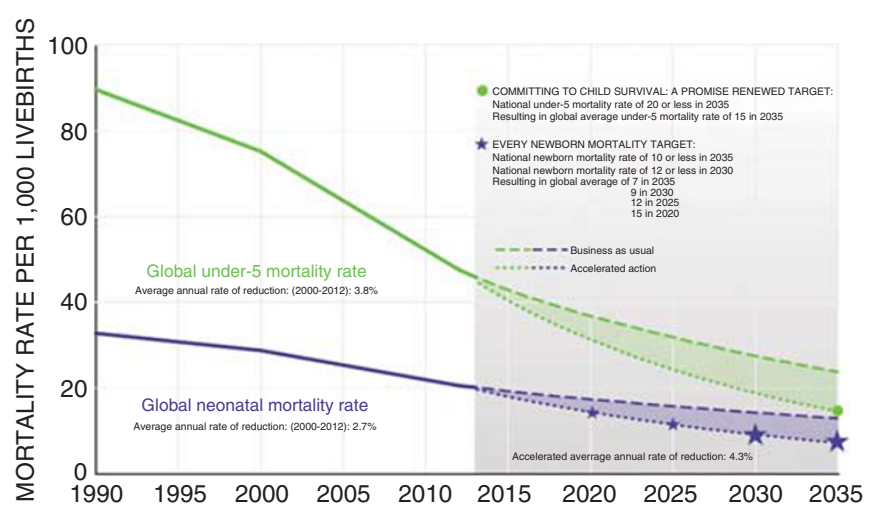

Figure 1. Targets for under-5 mortality and neonatal mortality per Every Newborn Action Plan. Available at https://www.everynewborn.org/ Documents/Every_Newborn_Action_Plan-EXECUTIVE_SUMMARYENGLISH_updated_July2014.pdf. Reprinted with permission from the World Health Organization. administering, and disseminating the training program as they saw fit (11).

In many countries, NRP was a driving force for the development of national initiatives to reduce neonatal and perinatal mortality through an action-oriented approach that trained a variety of providers, catalyzed acquisition of resuscitation equipment, and sensitized health authorities to the importance of newborn health (12). Implementation of NRP in various countries resulted in reduction in birthasphyxia-related mortality, in addition to increased use of bag-mask ventilation in the newborn resuscitation (13-15). However, training focused on relatively well-resourced hospital settings, and studies suggested that performance of neonatal resuscitation remained challenged by inadequate retention of skills after training, similar to what had been seen among US providers (16).

Another challenge to widespread adoption of NRP in lowresource settings was the assumption that resuscitation could not be accomplished without neonatal intensive care $(11,17,18)$. NRP is the educational program that translates the science of the International Liaison Committee on Resuscitation (ILCOR) Consensus on Science with Treatment Recommendations into practice. Much of the clinical research historically has originated from technologically developed settings. NRP courses taught in resource-limited settings were adapted to focus on the initial steps of resuscitation, bag-mask ventilation, and chest compressions, and omit discussion of intubation, medications, and umbilical line placement. Basic NRP was utilized in rural areas of countries that had adopted NRP nationally (11). Such adaptations of NRP improved both educational outcomes and skills when used to teach providers in low-resource settings $(15,19,20)$. The First Breath study of the National Institutes of Health Global Network for Maternal and Child Health used a modified NRP and essential newborn care package in rural communities of six countries with a multicenter, clusterrandomized trial design. This study included 62,366 infant births and resulted in a 30\% reduction in stillbirth rates in birth clusters that received the modified NRP training (21).

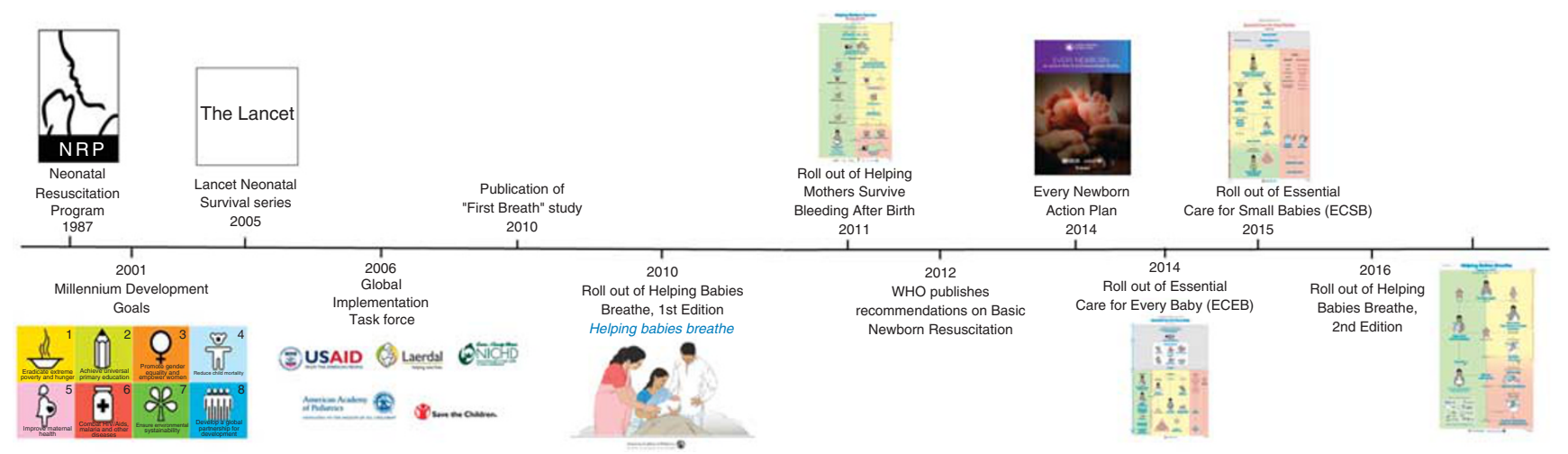

Figure 2. Timeline of programs to improve neonatal survival (Helping Babies Breathe cover and Action Plan, Essential Care for Every Baby and Essential Care for Small Babies Action Plans and NRP icon used with permission from the American Academy of Pediatrics. Helping Mothers Survive Action Plan used with permission from JHPIEGO). NRP, Neonatal Resuscitation Program. 
However, no reduction occurred in rates of early neonatal mortality or perinatal mortality.

These experiences identified that low-resource settings required a curriculum specifically designed and targeted for their needs. In 2006, the American Academy of Pediatrics organized a Global Implementation Task Force, which included stakeholders from a variety of disciplines committed to a worldwide reduction in neonatal mortality. Reviewing the science of resuscitation indicated that over $98 \%$ of babies responded with spontaneous breathing after basic resuscitation, including drying, warmth, stimulation, and bag-mask ventilation (Figure 3) $(8,18)$. However, studies in lowresource settings suggest that even more babies may require stimulation to breathe. The Task Force was charged with the mission of developing a standardized, simplified curriculum that combined the same scientific evidence base as NRP, with the goal of assuring that a person equipped and skilled is present at every birth no matter where a baby is born $(11,17)$.

The resulting basic resuscitation curriculum, Helping Babies Breathe (HBB), became available in 2010, and included elements of adult learning theory to encourage active learning, such as paired learning, hands-on practice, and feedback (22). The program was portable and low cost, and the resuscitation algorithm, or Action Plan, focused on stimulation, drying, clearing the airway as needed, and bag-mask ventilation with air-the interventions most often needed and effective in helping a baby to breathe. More advanced interventions, such as chest compressions, intubation, and medication administration, were omitted because they require high levels of skills and resources, rely on the availability of ongoing intensive care, and detract from a focus on what is feasible and most important. The algorithm emphasized that a baby should be breathing or receive ventilation by $1 \mathrm{~min}$ after birth. The concept of immediate help to breathe for all babies who fail to cry at birth, within The Golden Minute, was not only a valid scientific association to lower mortality but also an educational device to cause a paradigm shift. Instead of spending time evaluating a baby's condition first, then beginning help to breathe, interventions began immediately with sequential evaluation of crying, breathing, and heart rate as actions proceeded. Furthermore, elements of essential newborn care were incorporated into the curriculum, including encouragement of breastfeeding, cleanliness, and warmth at delivery.

The World Health Organization (WHO) released guidelines on basic newborn resuscitation in 2012, which were largely consistent with the recommendations and Action Plan of HBB (23). As the basis for the recommendations, the WHO used the 2010 International ILCOR evidence evaluations but further utilized an evidence evaluation that followed a modified GRADE system, specifically focusing on evidence from care environments in low- and middle-income countries. The new WHO guidelines also specifically mentioned $\mathrm{HBB}$ as an example of materials and programs for implementation.

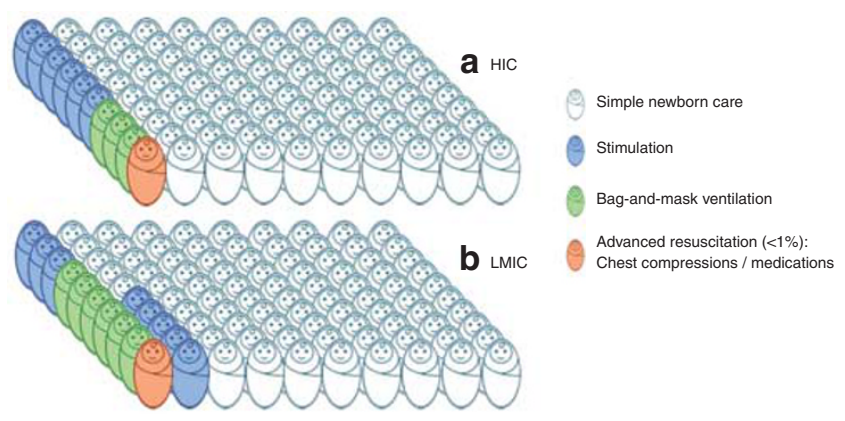

Figure 3. Need for resuscitation in high and lower-income settings. $(\mathbf{a}, \mathbf{b})$ Need for resuscitation in high- and lower-income settings. (a) In high-income settings, $\sim 5-10 \%$ of infants require stimulation at birth, $3-6 \%$ will require bag-mask ventilation, and less than $1 \%$ require advanced resuscitation (7). (b) In contrast, data from a large observational study performed in a rural hospital in Tanzania suggest that $85 \%$ of infants will require only simple newborn care, whereas $\sim 15 \%$ will need stimulation. $7 \%$ of the original population (approximately $50 \%$ of those requiring stimulation) will require bagmask ventilation and less than $1 \%$ will require advance care. (Adapted from Erdsal et al. (56)). HIC, high-income countries; LMIC, low and middle income countries.

\section{EDUCATIONAL OUTCOMES AFTER NEONATAL RESUSCITATION TRAINING}

An initial formative educational evaluation of $\mathrm{HBB}$ in Kenya and Pakistan showed that the course was well received and highly rated on surveys of satisfaction; in particular, newly trained facilitators and providers understood the importance of the "Golden Minute" (24). Providers showed gains in knowledge assessments from before and after the course. However, even after the course, perfect performance of the bag-mask ventilation checklist focused on the preparation and technique of bag-mask ventilation was low (24).

Additional studies have indicated that a workshop in HBB does improve knowledge and skills in basic neonatal resuscitation immediately after training (25-30). Several have examined the differences in performance based on the type of trainees assessed. These studies noted that physicians performed better in pre-workshop assessments of both knowledge and skills of basic resuscitation; however, after HBB training, nurses performed as well in simulation as physicians $(27,28,30)$. As a result, HBB training is now incorporated into pre-service education for not only physicians but also nurses, nurse-midwives, and other hospital providers in many countries. This is important as globally midwives perform the majority of deliveries and newborn resuscitations; non-physicians are often first responders to deliveries.

Although HBB has shown improvements in skills and knowledge in simulation after an initial training, these improved skills did not always translate into improvements in clinical practice. A study performed in Tanzania demonstrated that a higher proportion of providers passed the simulated assessments after an HBB course, compared with pre-course assessments (31). However, delivery room 
management after HBB training reflected no change in the numbers of babies being suctioned and/or ventilated after birth (31). Another study in Nepal video-taped delivery room performance after $\mathrm{HBB}$ training and showed that adherence to the Action Plan needed improvement: suction continued to be performed excessively and initiation of bag-mask ventilation was inadequate (32). Without specific activities to promote translation of new skills and knowledge into practice, behavior change may not occur.

Retention of skills after an initial neonatal resuscitation training has remained a challenge (33). Similar to observations of US providers after an NRP course, skills declined faster than knowledge and dropped to an unsatisfactory level after $\sim 3$ months (29). A study from Tanzania and Kenya assessed basic resuscitation skills $\sim 6$ months after an initial HBB training and showed that, while scores on knowledge tests remained $99 \%$, skills evaluations dropped from 99 to 81\% (ref. 34) A systematic review of neonatal resuscitation training in low-resource settings showed that significant declines in knowledge and skills were mitigated by refresher trainings (33). However, skills may decline at different rates, depending on various provider characteristics, such as the type of facility where the provider works, prior resuscitation training, and type of training (initial vs. refresher (35)). Although it is clear that frequent practice, such as low-dose/ high-intensity practice, may help retain skills after an initial training, general recommendations are unable to be made about optimal frequency, as the interval for practice to retain skills may vary by types of providers and frequency at which skills are used (36).

Several studies have evaluated implementation of low-dose/ high-frequency practice after $\mathrm{HBB}$ training. One study in Tanzania performed a pre/post-evaluation of clinical performance in the delivery room and early 24 -h neonatal mortality with weekly 3-5 min simulation practices supervised by an HBB master trainer (37). After initiation of frequent on-site practice by local midwives, 24-h mortality decreased from 11.1 to 7.2 per 1,000 live births $(P=0.04)$, and the rates of babies receiving stimulation and suction significantly increased (37). Another study from Nepal utilized quality improvement (QI) cycles with low-dose high-frequency practice methods and demonstrated that retention of neonatal resuscitation skill was associated with the routine practices of daily bag-mask skill check, preparation for resuscitation before every birth, use of a selfevaluation checklist, and attendance at weekly review meetings (38).

\section{EFFECTS AFTER IMPLEMENTATION OF NEONATAL RESUSCITATION}

In the first 5 years of program implementation, over 300,000 providers have been trained in HBB in 77 countries globally, with materials translated into 26 languages (39). Fifty-two countries have established nationally led programs (40). In the first phase of a national rollout in Tanzania, HBB was implemented in eight hospitals to evaluate whether the training program would enhance resuscitation skills and reduce early $(<24 \mathrm{~h})$ neonatal mortality and (misclassified) fresh stillbirths (41). Analysis of almost 80,000 births after HBB training demonstrated a $47 \%$ reduction in early neonatal deaths as well as a $24 \%$ reduction in rates of fresh stillbirth (41). Of interest, rates of babies who received stimulation and suction after birth increased, whereas rates of bag-mask ventilation decreased, likely due to the fact that most non-breathing infants were in primary apnea and responded to initial stimulation alone (41). A second study conducted in India demonstrated a decline in stillbirth rate by $24 \%$, with no change in neonatal mortality (25); this reduction in stillbirth rates likely reflects babies who were misclassified as fresh stillbirths who previously were not assessed and resuscitated. Finally, a third study in a tertiary hospital in Nepal used QI cycles to improve adherence to the HBB Action Plan and found a reduction in the intrapartum stillbirth rate (adjusted odds ratio (aOR) $0.46,95 \%$ confidence interval (CI) $0.32-0.66)$ and 24 -h neonatal mortality (aOR $0.51,95 \%$ CI $0.31-0.83$ (42).

The Global Network conducted a 2-year prospective pre-post study to evaluate the impact of a facility-based training package on regional perinatal outcomes including those that occurred in and out of facilities. Training included $\mathrm{HBB}$ and essential newborn care, using a train-the-trainer model in 71 health facilities covering 70,704 births in Belgaum and Nagpur, India, and Eldoret, Kenya (43). The study failed to demonstrate a reduction in regional perinatal mortality with training in facilities alone, but this was qualified by a significant differential improvement in neonatal mortality in low-birth-weight infants $(<2,500 \mathrm{~g})$ in Belgaum in both registry and HBB-trained facility births. Of note, over $50 \%$ of deliveries in Kenya occurred in home-based settings and therefore may have been unaffected by the intervention, thereby under-recognizing the effects of $\mathrm{HBB}$ training on perinatal mortality in the facilities where training did occur. The perinatal mortality rate and fresh stillbirth rate in the Kenyan HBB-trained facilities decreased. In addition, the perinatal mortality rate was reduced by $34 \%$ and the stillbirth rate by $54 \%$ in one of the Indian sites. A very short baseline period of data collection (2 months) prior to the intervention may have further complicated interpretation of factors producing the differential effect (43).

A systematic review performed by Pammi et al. (44) evaluated whether the implementation of a standardized formal neonatal resuscitation training program (including HBB or modified NRP) in low- and middle-income countries improved neonatal outcomes, and found that early neonatal mortality ( $<7$ days) decreased by $15 \%$ (risk ratio 0.85 ( $95 \%$ CI $0.75-0.96$ ) with a number needed to benefit of 227) with reduction of 28 -day mortality by $45 \%$ (risk ratio 0.55 (95\% CI 0.33-0.91)). However, whereas follow-up studies suggest normal neurodevelopment in resuscitation survivors, the effects of resuscitation in the context of birth asphyxia and 


\section{Review | Kamath-Rayne et al.}

impact on long-term neurodevelopmental outcomes remain uncertain (44).

\section{ONGOING IMPROVEMENT FOR THE CARE OF MOTHERS AND BABIES}

In 2010, the HBB Global Development Alliance was founded by five core member organizations, which included the American Academy of Pediatrics, the United States Agency for International Development, Laerdal Global Health, Save the Children, and the Eunice Kennedy Shriver National Institute for Child Health and Human Development (40). The goal of this public/private partnership was to work together toward achieving a significant reduction in neonatal morbidity and mortality by strengthening the performance of providers who prevent and manage birth asphyxia in lowresource settings (40). Despite the successes of implementation of neonatal resuscitation education, training providers in and of itself is insufficient to close the quality gaps for newborn care and to reach the goals set forth by the Every Newborn Action Plan. Hill et al. (45) developed a framework for understanding and developing strategies to overcome these gaps; this framework categorizes the major gaps to overcome as provider competencies, essential commodities, organization of care processes, health information systems, governance and national policies, and lack of QI capacity with health-care systems. More recently, the WHO developed a framework for improving the quality of care for mothers and newborns around the time of childbirth that focused on six strategic areas (clinical guidelines, standards of care, effective interventions, measures of quality of care, relevant research, and capacity-building) (46). The goal is that these six strategic areas will enable an evidence-based approach to guide interventions to improve the quality of care for mothers and newborns.

QI strategies have been shown in several single-center studies to be successful in decreasing maternal and neonatal morbidity and mortality $(40,42,47-49)$. The power of training followed by a commitment to QI was exemplified in Nepal, where formation of QI teams, development of QI goals, HBB trainings, daily skill checks, and refresher trainings resulted in the intrapartum stillbirth rate decreasing from 9.0 to 3.2 per thousand deliveries, and 24-h neonatal mortality decreasing from 5.2 to 1.9 per thousand live births (42).

In the Philippines, an observational study of resuscitation and newborn care practices prior to the introduction of $\mathrm{HBB}$ indicated that doctors trained in newborn resuscitation were 2.5 times more likely to unnecessarily suction vigorous newborns, and that newborn care practices were performed, but in an inappropriate sequence that minimized skin-to-skin care (50). For example, the majority of mothers $(68.2 \%)$ did put their babies to breast, but the babies were taken from their mothers 2 min later for other newborn care interventions (50). This prompted the development of an Essential Newborn Care protocol, which was the result of a collaborative process between the Department of Health, stakeholders, and local experts (50).
In 2009, a large-scale maternal-newborn QI intervention in Tanzania implemented training in basic and emergency obstetric services and routine delivery care, provision of essential equipment, supportive supervision of care in health facilities, QI approach in facilities, and improvements to the national health information systems (51). Of note, this was prior to a national rollout of HBB. The results showed that provision of essential newborn care significantly improved, as did health worker knowledge; however, resuscitation skills using a newborn mannequin remained low (51).

Focused QI efforts by a Neonatal Task Force in a rural Kenyan hospital demonstrated a reduction in birth-asphyxiarelated mortality by $53 \%$, from 14.7 to 7.1 per 1,000 live births (42). The Task Force tested interventions that included HBB trainings and simulation practice, a change in the pediatrics paging policy for delivery room attendance, and implementation of a data collection system (47). By tracking their results, the Task Force was also able to demonstrate an increase in asphyxia-related mortality when well-trained staff were transferred to other departments in the hospital. Presentation of these data to the hospital administration allowed change of policies and retention of skilled staff experienced in resuscitation on labor and delivery (47).

Whereas QI efforts have been successful in low-resource settings, challenges remain at introducing QI concepts, where technical terminology is less important than general concepts and understanding of how to implement and track results after changes. An Improvement Guide developed by the Survive and Thrive Global Development Alliance was released in late 2016 and designed to be used in facilities to aid in understanding simple QI concepts, and in planning and implementing interventions (52).

\section{USING RESEARCH TO FURTHER IMPROVE NEONATAL SURVIVAL}

In 2012, ILCOR published a paper laying out gaps in knowledge to encourage further research in neonatal resuscitation, and included a section of unanswered questions specifically related to low-resource settings (53). The 2015 ILCOR Consensus on Science with Treatment Recommendations (CoSTR) used the GRADE system for evidence evaluation, similar to its use for evaluating recommendations for the WHO Basic Neonatal Resuscitation Guidelines in 2012, and included questions related to low-resource settings.

$\mathrm{HBB}$ is updated on a 5-year cycle, beginning with the second edition released in the fall of 2016, to incorporate the revised scientific recommendations from the corresponding ILCOR guideline cycle (54). These scientific changes include the recommendation that no suctioning is needed before drying of babies born through meconium-stained amniotic fluid, whether crying or not, and a de-emphasis on oropharyngeal suctioning overall. Stronger evidence for delayed cord clamping ensured its continued inclusion in the curriculum. Further inputs included an Utstein-style implementation meeting of key stakeholders in 2015, which suggested an increased sensitization to QI, including ongoing 


\section{Neonatal resuscitation in global health Review}

identification of gaps in care and critical monitoring targets. A survey of frontline providers $(N=102)$ also suggested emphasis on building competence in neonatal resuscitation skills, systems for ongoing practice, and improving support for facilitators. Delphi review of the materials further underscored communication and reinforced the importance of facilitators seeking partnerships with Ministries of Health, professional societies, and in-country educational institutions. Focus group discussions with participants of field tests in India and Sierra Leone indicated enthusiasm for the hands-on approach, the skill of facilitators, and learning methodology, but that implementation and QI are ongoing challenges, specifically for rural areas.

Careful consideration of revisions has taken into account the many successes of the program, while incorporating improvements based on research around ongoing systems for practice and retention of skills, QI, and implementation strategies. HBB facilitators are now challenged to not only run HBB workshops but also develop long-term relationships with facilitators and providers seeking to sustain the gains made after an initial HBB workshop. Strengthened support for facilitators includes an updated Helping Babies Survive (HBS) website (http://hbs.aap.org), with an International Resources section where course materials can be downloaded free of charge, and interactive webinars to support a community of learning.

\section{DISCUSSION}

An estimated two-thirds of the world's 2.7 million newborn deaths may be prevented with basic quality care at birth and during the postnatal period (55). On a global scale, many successes have been achieved in the implementation of neonatal resuscitation: decreased neonatal mortality, decreased still birth rates, and increased use of alternative cadres of providers. However, significant bottlenecks and barriers remain to realizing the goals set forth by the Every Newborn Action Plan. For neonatal resuscitation in particular, countries in Africa and Asia ranked improving workforce performance, availability of essential commodities, and well-integrated health service delivery as highest priority (55).

HBB and its accompanying programs that equip providers with the requisite skills to care for babies before, during, and after birth have now been subsumed under the umbrella of HBS and Helping Mothers Survive. Because of a greater understanding that neonatal survival is intimately intertwined with not only medical science but also educational effectiveness and local implementation, efforts are shifting from rapid rollout in new countries to a greater emphasis on deepening and expanding support in countries where HBB has already been introduced with the objective of achieving high-quality care, sustainability, and impact (40). Further collaborative efforts are needed to study the possible synergistic effects of HBS and Helping Mothers Survive programs to improve care for both mothers and babies across the perinatal continuum, in addition to the ongoing contribution of implementation science. Although there are many successes to celebrate, there is still much work to be done such that efforts to improve newborn care and reduce neonatal mortality will reach every newborn.

\section{DISCLOSURE}

Kamath-Rayne, Berkelhamer, and Niermeyer are on the American Academy of Pediatrics Helping Babies Survive Planning Group, which provides scientific oversight for Helping Babies Breathe. The American Academy of Pediatrics did not contribute to the writing of this manuscript. The remaining authors declare no conflict of interest.

\section{REFERENCES}

1. Gaffey MF, Das JK, Bhutta ZA. Millennium Development Goals 4 and 5: past and future progress. Semin Fetal Neonatal Med 2015;20:285-92.

2. Liu L, Oza S, Hogan D, et al. Global, regional, and national causes of child mortality in 2000-13, with projections to inform post-2015 priorities: an updated systematic analysis. Lancet 2015;385:430-40.

3. World Health Organization, UNICEF Every Newborn: an Action Plan to End Preventable Deaths, 2014. Available at https://www.everynewborn. org/Documents/Every_Newborn_Action_Plan-EXECUTIVE_SUMMARYENGLISH_updated_July2014.pdf. Accessed 19 July 2016.

4. Lawn JE, Blencowe H, Waiswa P, et al. Stillbirths: rates, risk factors, and acceleration towards 2030. Lancet 2016;387:587-603.

5. Goldenberg RL, McClure EM, Jobe AH, Kamath-Rayne BD, Gravette MG, Rubens CE. Stillbirths and neonatal mortality as outcomes. Int J Gynaecol Obstet 2013;123:252-3.

6. Kamath-Rayne BD, Griffin JB, Moran K, et al. Resuscitation and obstetrical care to reduce intrapartum-related neonatal deaths: a MANDATE study. Matern Child Health J 2015;19:1853-63.

7. Lee AC, Cousens S, Wall SN, et al. Neonatal resuscitation and immediate newborn assessment and stimulation for the prevention of neonatal deaths: a systematic review, meta-analysis and Delphi estimation of mortality effect. BMC Public Health 2011;11(Suppl 3):S12.

8. Wall SN, Lee AC, Carlo W, et al. Reducing intrapartum-related neonatal deaths in low- and middle-income countries-what works? Semin Perinatol 2010;34:395-407.

9. Yoshida S, Martines J, Lawn JE, et al. Setting research priorities to improve global newborn health and prevent stillbirths by 2025. J Glob Health 2016;6:010508.

10. Halamek L. The genesis, adaptation, and evolution of the Neonatal Resuscitation Program. NeoReviews 2008;9:142-9.

11. Niermeyer S. From the neonatal resuscitation program to Helping Babies Breathe: global impact of educational programs in neonatal resuscitation. Semin Fetal Neonatal Med 2015;20:300-8.

12. Deorari AK, Paul VK, Singh M, Vidyasagar D. The national movement of neonatal resuscitation in India. J Trop Pediatr 2000;46:315-7.

13. Deorari AK, Paul VK, Singh M, Vidyasagar D. Impact of education and training on neonatal resuscitation practices in 14 teaching hospitals in India. Ann Trop Paediatr 2001;21:29-33.

14. Gill CJ, Phiri-Mazala G, Guerina NG, et al. Effect of training traditional birth attendants on neonatal mortality (Lufwanyama Neonatal Survival Project): randomised controlled study. Br Med J 2011;342:d346.

15. Xu T, Wang $\mathrm{H}$, Gong $\mathrm{L}$, et al. The impact of an intervention package promoting effective neonatal resuscitation training in rural China. Resuscitation 2014;85:253-9.

16. Carlo WA, Wright LL, Chomba E, et al. Educational impact of the neonatal resuscitation program in low-risk delivery centers in a developing country. J Pediatr 2009;154:504-8 e5.

17. Little G, Keenan W, Singhal N, Niermeyer S. Helping Babies Breathe: evolution of a global neonatal resuscitation program for resourcelimited areas. NeoReviews 2015;15:e369-80.

18. Newton O, English M. Newborn resuscitation: defining best practice for low-income settings. Trans R Soc Trop Med Hyg 2006;100:899-908. 
19. Bookman L, Engmann C, Srofenyoh E, et al. Educational impact of a hospital-based neonatal resuscitation program in Ghana. Resuscitation 2010;81:1180-2.

20. Trevisanuto D, Bertuola F, Lanzoni P, et al. Effect of a neonatal resuscitation course on healthcare providers' performances assessed by video recording in a low-resource setting. PLoS ONE 2015;10:e0144443.

21. Carlo WA, Goudar SS, Jehan I, et al. Newborn-care training and perinatal mortality in developing countries. N Engl J Med 2010;362:614-23.

22. Niermeyer S, Keenan W, Little G, Singhal N. Helping Babies Breathe: Facilitator Flip Chart: American Academy of Pediatrics, Laerdal Global Health. Available at http://internationalresources.aap.org/Resource/ ShowFile?documentName =hbb_flipchart_english.pdf. Accessed 2010.

23. World Health Organization. Guidelines on basic newborn resuscitation 2012. Available at https://www.ncbi.nlm.nih.gov/books/NBK137872/pdf/ Bookshelf_NBK137872.pdf. Accessed 5 September 2017.

24. Singhal N, Lockyer J, Fidler H, et al. Helping Babies Breathe: global neonatal resuscitation program development and formative educational evaluation. Resuscitation 2012;83:90-6.

25. Goudar SS, Somannavar MS, Clark R, et al. Stillbirth and newborn mortality in India after Helping Babies Breathe training. Pediatrics 2013;131:e344-52.

26. Me Arabi A, Ibrahim SA, Ahmed SE, et al. Skills retention in Sudanese village midwives 1 year following Helping Babies Breathe training. Arch Dis Child 2016;101:439-2.

27. Rule ARL, Tabangin ME, Cheruiyot D, Mueri P, Kamath-Rayne BD. Just-in-Time training to maintain neonatal resuscitation skills after Helping Babies Breathe training in rural Kenya (under review).

28. Hoban R, Bucher S, Neuman I, Chen M, Tesfaye N, Spector JM. 'helping Babies Breathe' training in sub-saharan Africa: educational impact and learner impressions. J Trop Pediatr 2013;59:180-6.

29. Musafili A, Essen B, Baribwira C, Rukundo A, Persson LA. Evaluating Helping Babies Breathe: training for healthcare workers at hospitals in Rwanda. Acta Paediatr 2013;102:e34-8.

30. Seto TL, Tabangin ME, Josyula S, Taylor KK, Vasquez JC, KamathRayne BD. Educational outcomes of Helping Babies Breathe training at a community hospital in Honduras. Perspect Med Educ 2015;4:225-32.

31. Ersdal HL, Vossius C, Bayo E, et al. A one-day "Helping Babies Breathe" course improves simulated performance but not clinical management of neonates. Resuscitation 2013;84:1422-7.

32. Lindback C, Kc A, Wrammert J, Vitrakoti R, Ewald U, Malqvist M. Poor adherence to neonatal resuscitation guidelines exposed; an observational study using camera surveillance at a tertiary hospital in Nepal. BMC Pediatr 2014;14:233.

33. Reisman J, Arlington L, Jensen L, Louis H, Suarez-Rebling D, Nelson BD. Newborn resuscitation training in resource-limited settings: a systematic literature review. Pediatrics 2016;138.pii:e20154490.

34. Bang A, Patel A, Bellad R, et al. Helping Babies Breathe (HBB) training: what happens to knowledge and skills over time? BMC Pregnancy Childbirth 2016;16:364.

35. Bang A, Bellad R, Gisore P, et al. Implementation and evaluation of the Helping Babies Breathe curriculum in three resource limited settings: does Helping Babies Breathe save lives? A study protocol. BMC Pregnancy Childbirth 2014;14:116.

36. Ersdal HL, Singhal N. Resuscitation in resource-limited settings. Semin Fetal Neonatal Med 2013;18:373-8.

37. Mduma E, Ersdal H, Svensen E, Kidanto H, Auestad B, Perlman J. Frequent brief on-site simulation training and reduction in 24-h neonatal mortality-an educational intervention study. Resuscitation 2015;93:1-7.

38. KC A, Wrammert J, Nelin V, et al. Evaluation of Helping Babies Breathe Quality Improvement Cycle (HBB-QIC) on retention of neonatal resuscitation skills six month after training in a low-income setting like Nepal. BMC Pediatr 2017;17:103.

39. Berkelhamer SK, Kamath-Rayne BD, Niermeyer S. Neonatal resuscitation in low-resource settings. Clin Perinatol 2016;43:573-91.
40. Helping Babies Breathe Global Development Alliance. Helping Babies Breathe: Lessons learned guiding the way forward, 2015. Available at http://www.helpingbabiesbreathe.org/docs/HBB-Report-2010-2015.pdf. Accessed 5 September 2017.

41. Msemo G, Massawe A, Mmbando D, et al. Newborn mortality and fresh stillbirth rates in Tanzania after helping babies breathe training. Pediatrics 2013;131:e353-60.

42. KC A, Wrammert J, Clark RB, et al. Reducing perinatal mortality in Nepal using Helping Babies Breathe. Pediatrics 2016;137:e20150117.

43. Bellad RM, Bang A, Carlo WA, et al. A pre-post study of a multi-country scale up of resuscitation training of facility birth attendants: does Helping Babies Breathe training save lives? BMC Pregnancy Childbirth 2016;16: 222.

44. Pammi M, Dempsey EM, Ryan CA, Barrington KJ. Newborn resuscitation training programmes reduce early neonatal mortality. Neonatology 2016;110:210-4.

45. Hill K, Clark P, Narayanan I, Wright LL, D V. Improving Quality of Basic Newborn Resuscitation in Low-Resource Settings: A Framework for Managers and Skilled Birth Attendants. USAID ASSIST Project: Bethesda, MD, 2014.

46. World Health Organization Standards for Improving Quality of Maternal and Newborn Care in Health Facilities. Geneva, Switzerland, 2016. Available at http://www.who.int/maternal_child_adolescent/documents/ improving-maternal-newborn-care-quality/en/. Accessed 5 September 2017.

47. Rule ARL, Maina E, Cheruiyot D, Mueri P, Simmons JM, Kamath-Rayne BD. Using quality improvement to decrease birth asphyxia rates after Helping Babies Breathe in Kenya (under review).

48. Srofenyoh E, Ivester T, Engmann C, Olufolabi A, Bookman L, Owen M. Advancing obstetric and neonatal care in a regional hospital in Ghana via continuous quality improvement. Int J Gynaecol Obstet 2012;116:17-21.

49. Van Heerden C, Maree C, Janse van Rensburg ES. Strategies to sustain a quality improvement initiative in neonatal resuscitation. Afr J Prim Health Care Fam Med 2016;8:e1-10.

50. Sobel HL, Silvestre MA, Mantaring 3rd JB, Oliveros YE, Nyunt US. Immediate newborn care practices delay thermoregulation and breastfeeding initiation. Acta Paediatr 2011;100:1127-33.

51. Makene CL, Plotkin M, Currie S, et al. Improvements in newborn care and newborn resuscitation following a quality improvement program at scale: results from a before and after study in Tanzania. BMC Pregnancy Childbirth 2014;14:381.

52. Bose C, J Hermida. Improving Care of Mothers and Babies: A Guide for Improvement Teams. Survive \& Thrive Global Development Alliance, American Academy of Pediatrics, University Research Co LLC. 2016. Available at http://internationalresources.aap.org/Resource/ShowFile? documentName=Improving\%20 Care\%20of\%20Mothers\%20and $\%$ 20Babies_Asia\%20Version_Eng.\%202016.pdf. Accessed 5 September 2017.

53. Perlman J, Kattwinkel J, Wyllie J, Guinsburg R, Velaphi S. Neonatal resuscitation: in pursuit of evidence gaps in knowledge. Resuscitation 2012;83:545-0.

54. Niermeyer S, Kamath-Rayne B, Keenan W, Little G, Singhal N, Visick M. Helping Babies Breathe: Facilitator Flip Chart: American Academy of Pediatrics, Laerdal Gloval Health; 2016, 2nd (edn). Available at $\mathrm{http}$ ///internationalresources.aap.org/Resource/ShowFile?documentName = HBB_Flipbook_Second_Edition_20-00371_Rev_E.pdf. Accessed 5 September 2017.

55. Enweronu-Laryea C, Dickson KE, Moxon SG, et al. Basic newborn care and neonatal resuscitation: a multi-country analysis of health system bottlenecks and potential solutions. BMC Pregnancy Childbirth 2015; 15(Suppl 2):S4.

56. Erdsal HL, Mduma E, Svensen E, Perlman JM. Early initiation of basic resuscitation interventions including face mask ventilation may reduce birth asphyxia related mortality in low-income countries: a prospective descriptive observational study. Resuscitation 2012;83:869-73. 